\title{
Does root cutting in seedlings before transplanting affect growth and yield of lowland rice (Oryza sativa L.)?
}

\author{
AfricaRice

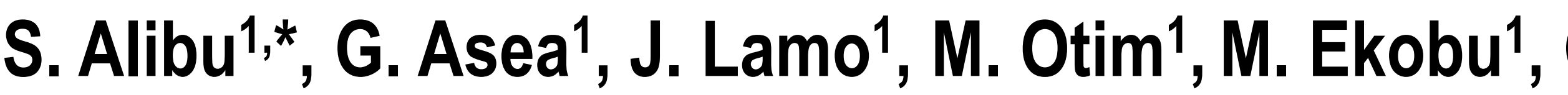 \\ G. Onaga ${ }^{1}$, \\ S. Adur ${ }^{1}$, T. Tsuboi ${ }^{2}$
}

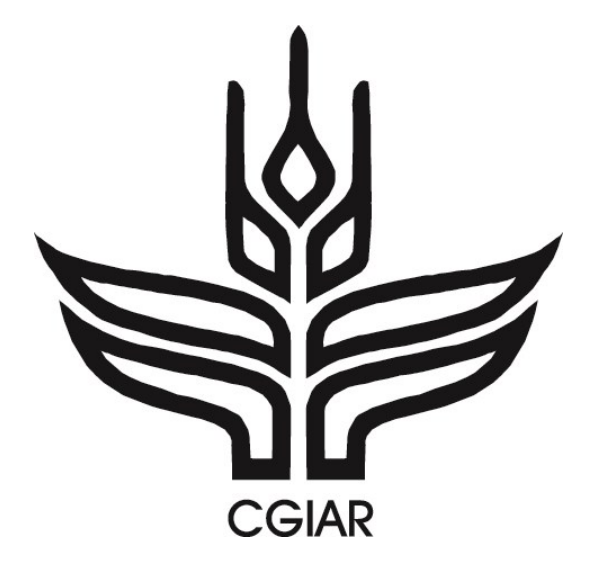

${ }^{1}$ National Crops Resources Research Institute (NaCRRI). P.O Box 7084, Kampala, Uganda

2Japan International Cooperation Agency (JICA), Uganda Office. P.O Box 12162, Kampala, Uganda

\section{Introduction}

Lowland rice cultivation is just beginning to take root in much of Sub-Sahara Africa, but transplanting is unpopular as it is laborintensive and labor is becoming scarce and expensive. A substantial share of labor and time goes into preparing rice seedlings before transplanting, including carefully uprooting and washing the seedlings to minimize root injury. This study examined whether cutting the roots of rice seedlings before transplanting affects growth and yield of lowland rice.

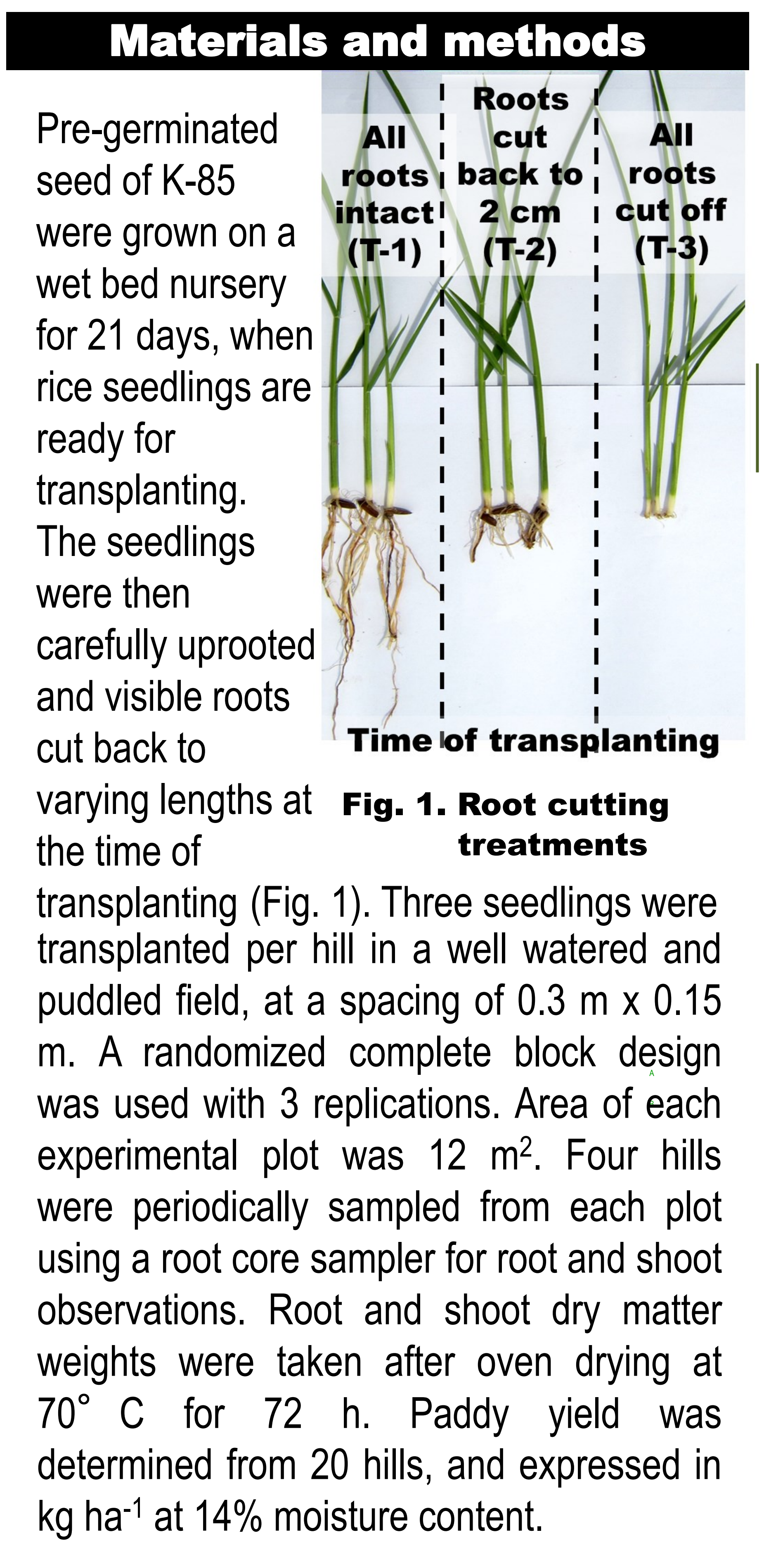

\section{Aoknowledgments}

$$
\text { N }
$$

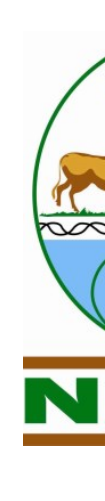

NATIONAL AGRICULTURAL RESEARCH ORGANIZATION

\section{Results and discussion}

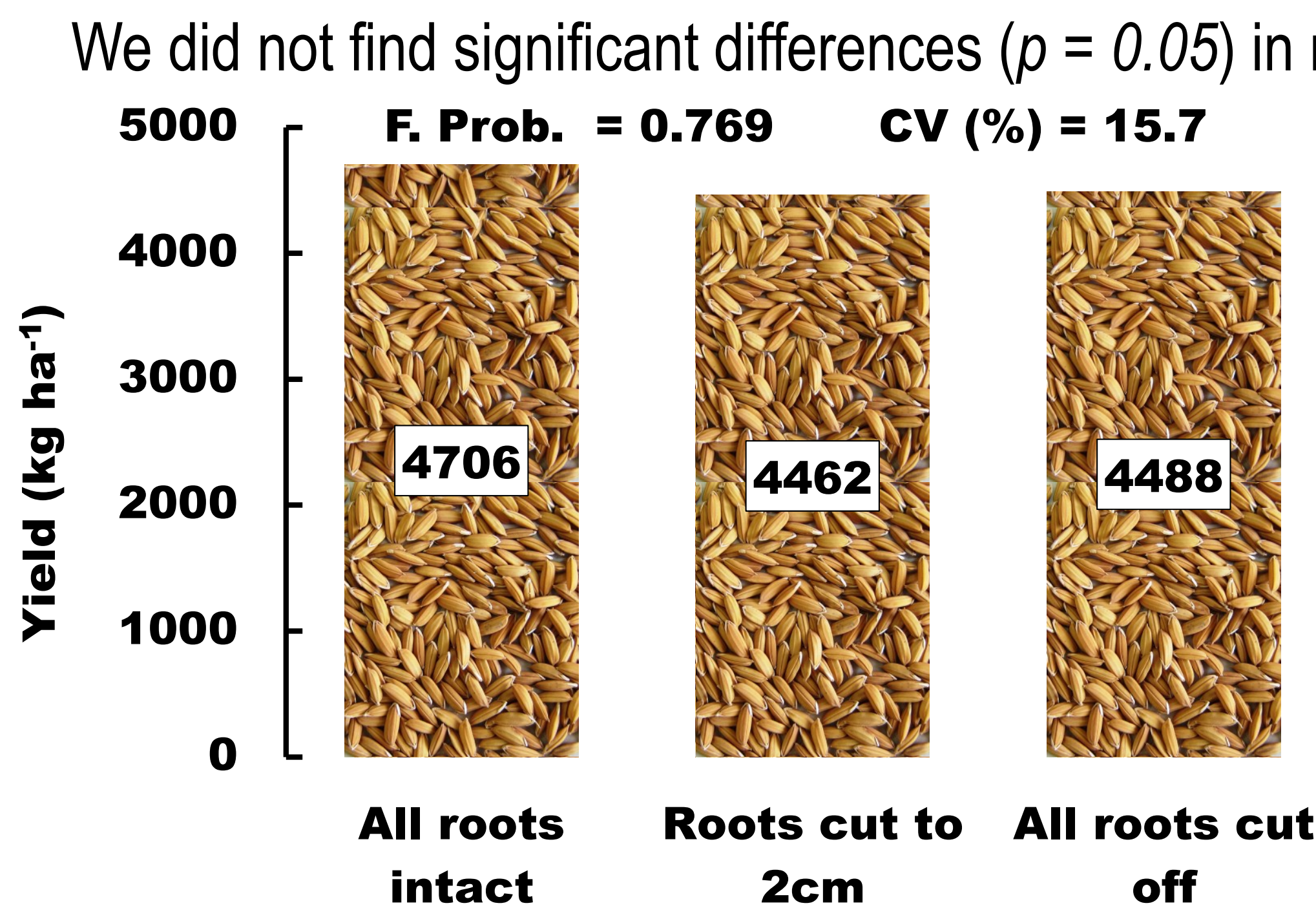

Fig. 2. Paddy yield of lowland rice in which roots were cut back at time of transplanting

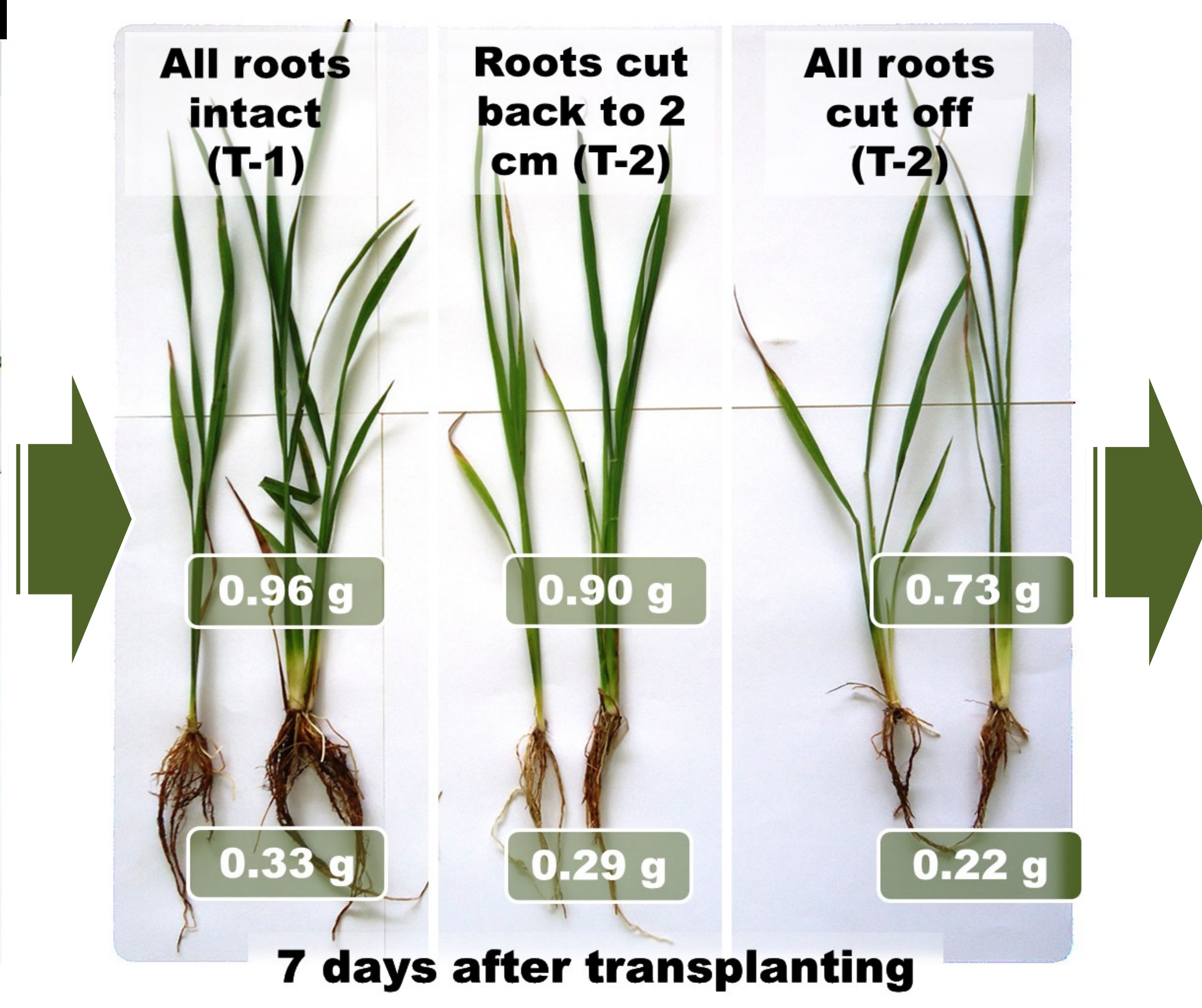

treatments at just 14 days after transplanting (Fig. 3). Consequently, cutting roots of rice seedlings before transplanting did not have a significant effect on paddy yield (Fig 2).

These findings are consistent with those of Ikeda et al. (2007) who showed that root pruning only affects growth and yield of lowland rice when seedlings are transplanted in extremely stressful conditions, where standing water is absent.

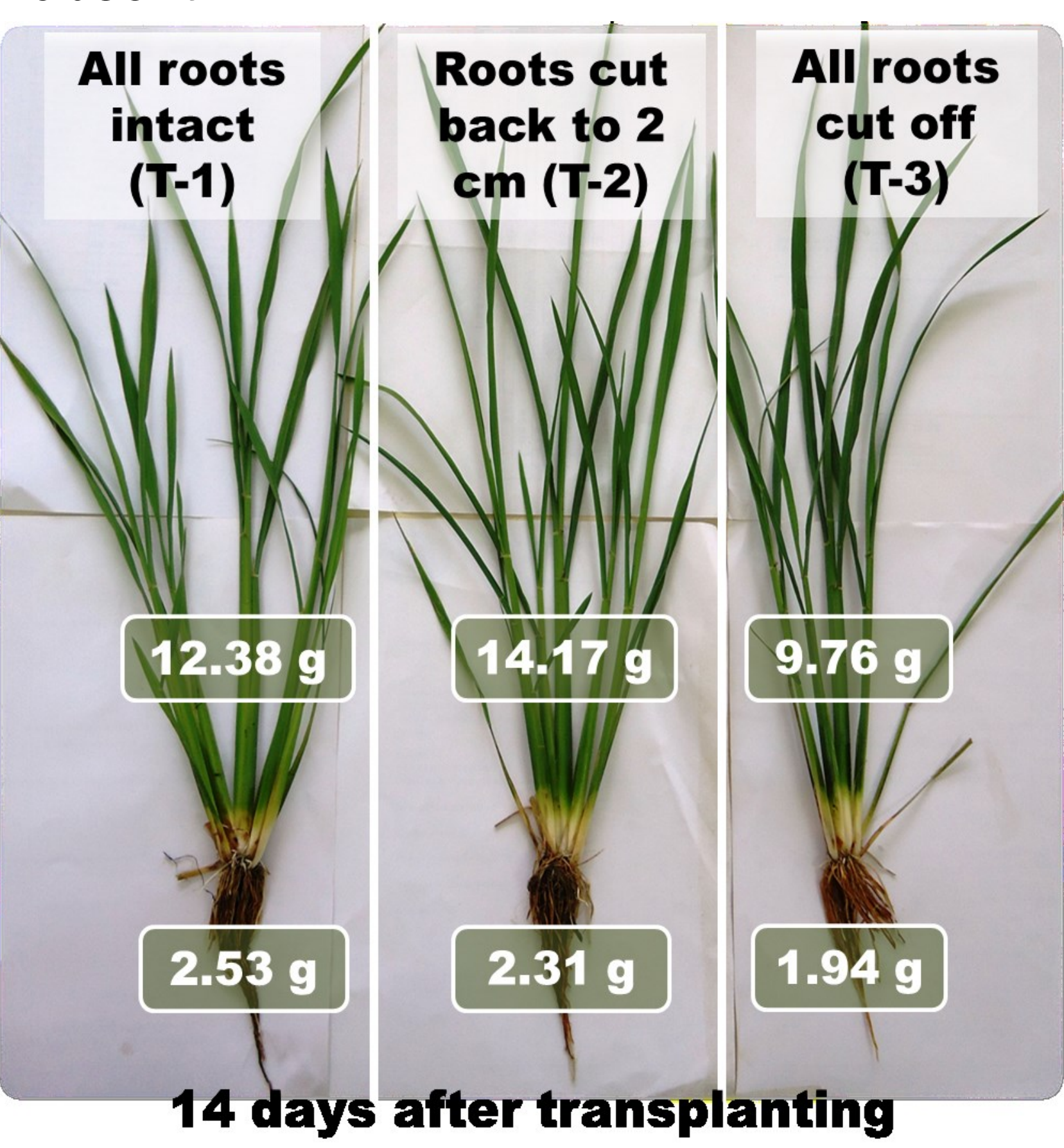

Fig. 3. Root growth of lowland rice in which roots were cut back at time of transplanting. Inset are average root and shoot dry matter weights per hill.

\section{Conclusion}

Our findings show that rice seedlings can quickly recover normal root growth when transplanted in a well-watered and puddled field, even if all visible roots are cut off at the time of transplanting.

This suggests that farmers can quickly dredge up rice seedlings from nurseries, using a sharp implement (Fig. 4), mindless of the consequences of any roots cut, thus minimize labor requirements and ensure timely transplanting.

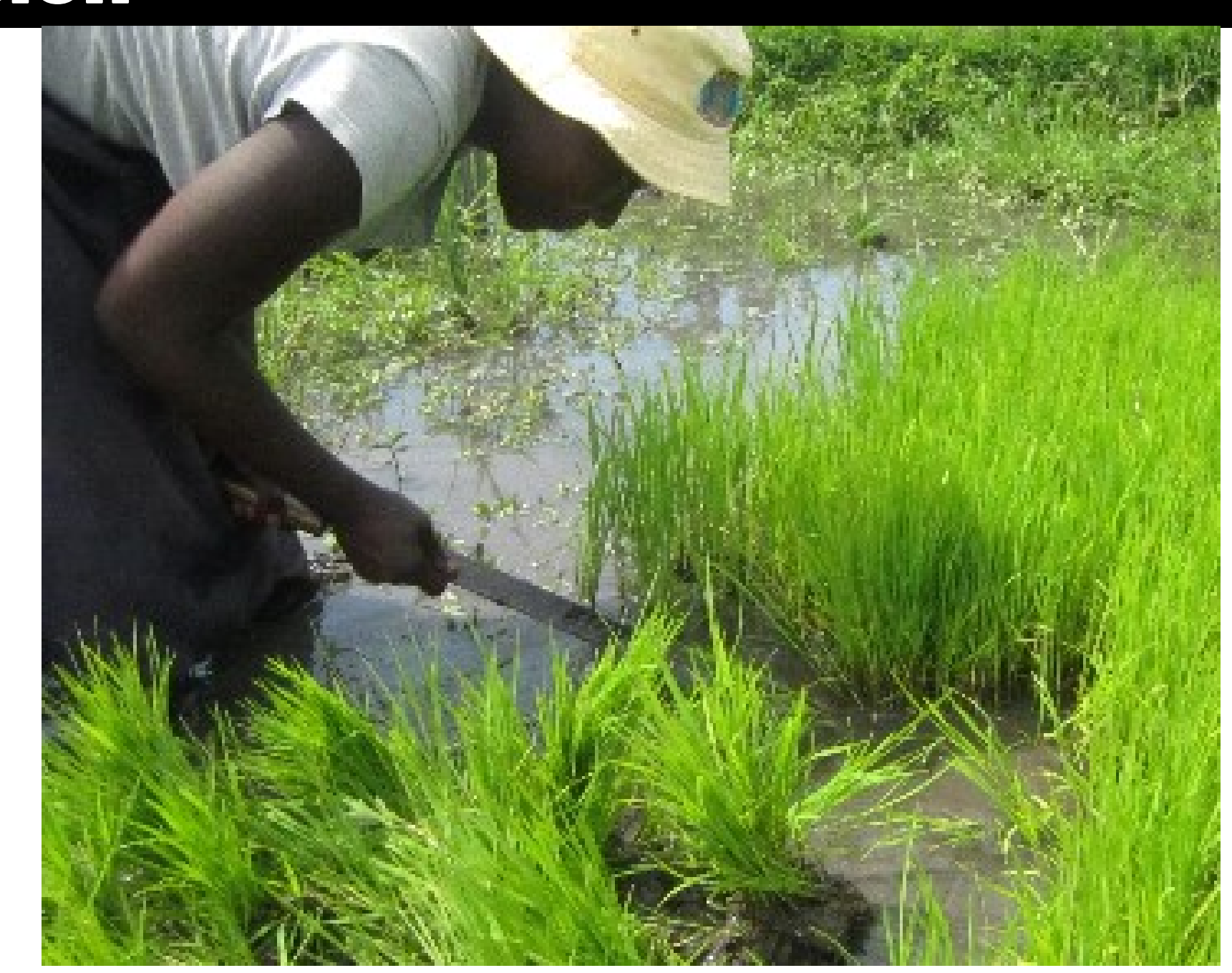

Fig. 4. A farmer dredges up rice seedlings using a machete

\section{Reference}

Ikeda H, Kamoshita A, and Manabe T. 2007. Genetic analysis of rooting ability of transplanted rice (Oryza sativa L.) under different water conditions. J. Exp. Bot. 58 (2): 309-318.

\section{Gontagt Information}

Name : Simon Alibu

Email: simoalibu@hotmail.com

Organization: National Crops Resources Research Institute (NaCRRI). P.O Box 7084, Kampala, Uganda Tel: +256-772-397674 (cell) 